\title{
The Fall and Fracture in Early Stroke Patients and The Evaluation of Influencing Factors (1-Year Follow-Up)
}

\author{
Tuba Erdem Sultanoğlu' ${ }^{1 \oplus}$, Alev Çevikol ${ }^{2 \oplus}$, Hasan Sultanoğlu ${ }^{3 \oplus}$, Fatma Aytül Çakcı ${ }^{\circledR}$ \\ 'Şehitkamil State Hospital, Department of Physical Medicine \& Rehabilitation, Gaziantep, Turkey \\ 2Diskapı YIIIıım Beyazıt Education and Research Hospital, Department of Physical Medicine \& Rehabilitation, Ankara, Turkey \\ ${ }^{3}$ Ersin Arslan Education and Research Hospital, Department of Emergency Medicine, Gaziantep, Turkey \\ Address for Correspondence: Tuba Erdem Sultanoğlu, E-mail: drtubaerdem@gmail.com \\ Received: 13.05.2019; Accepted: 15.05.2019; Available Online Date: 21.08.2019 \\ (OCopyright 2018 by Dokuz Eylül University, Institute of Health Sciences - Available online at www.jbachs.org \\ Cite this article as: Erdem Sultanoğlu T, Çevikol A, Sultanoğlu Ha, Çakcı FA. The Fall and Fracture in Early Stroke Patients and The Evaluation of Influencing Factors (1-Year Follow-Up). J Basic
} Clin Health Sci 2019; 3:121-127.

$26^{\text {th }}$ National Physical Medicine and Rehabilitation Congress (2017 Antalya).

\begin{abstract}
Objective: This study aims to examine the factors that may affect the falls and fractures which was in stroke patients during the rehabilitation phase and follow-up phase in the first year after discharge. It was aimed to assess the frequency of falls and fractures in early period after stroke.

Materials and Methods: This study which was conducted between 2011-2013, included 50 patients who were admitted to and hospitalized at the rehabilitation clinic between the first two weeks and six months since the date of the stroke, who had sitting balance or were suitable to undergo ambulation. The demographic and clinical characteristics, complications and previous histories of the patients were recorded and physical examinations were performed. The patients were called for follow-up at the sixth month and first year after discharge; the number of falls and presence, number and location of fractures associated with falls were queried.

Results: $76 \%$ of the patients returned for follow-up at the sixth month; $70 \%$ for follow-up at the first year. Fall rates were $2 \%$ during the clinical follow-up; $26.3 \%$ during the first sixth months; $25.7 \%$ between the $6^{\text {th }}$ and $12^{\text {th }}$ months. 1 of 35 patients had wrist fracture on the hemiplegic side during the first six months. The patients were divided into two groups as fallen and not fallen.

Conclusion: Fall after stroke is common during acute period, rehabilitation phase and chronic period. Early rehabilitation after stroke may increase balance and upper limb motor functions leading to lower rates of falls and fractures. Progressed osteoporosis and weakened bones leading to increased risk of fractures may be observed with longer follow-up periods.
\end{abstract}

Keywords: Stroke, fall, fracture

\section{INTRODUCTION}

Stroke is a leading cause of adult disabilities that cause significant problems in psychological, physical, social aspects of life, and impair quality of life. Fall after stroke is common during acute period, rehabilitation phase and chronic period (1) and also fall is one of the most fearful complications during rehabilitation process of stroke patients who have physical and cognitive problems (2). $14-65 \%$ of patients who had a stroke and hospitalized fall at least once during hospitalization. Adults with stroke fall at almost twice the rate of their peers in the first year after discharge and approximately $5 \%$ experience fractures or serious injuries $(3,4)$. Studies report fracture rates of $1-15 \%$ after stroke due to falls (5). Environmental and individual risk factors that may cause falls after stroke should be determined. Necessary measures should be taken to avoid falls and consequent fractures using a multidisciplinary approach including medical treatment(reviewing the drugs used, determining and treating accompanying comorbid diseases), physiotherapy (balance, standing and mobilization), occupational therapy (functionality, independence and behavior modification), diet recommendations (vitamin D and Ca supplementation, general nutrition recommendations), foot and ankle exercises, shoe and orthoses selection and, clinical psychology (anxiety, depression and fear of falling) (2).

This study aims to examine the factors and that may affect the falls and fractures which was in stroke patients during the rehabilitation phase and follow-up phase in the first year after discharge. It was aimed to assess the frequency of falls and fractures in early period after stroke. 


\section{MATERIALS and METHODS}

In this cross-sectional study, which was conducted between 2011 and 2013, included 50 patients (27 females; 23 males; mean age $60 \pm 13$ years) who were admitted to and hospitalized at the rehabilitation clinic between the first two weeks and six months since the date of the stroke, who had sitting balance or were suitable to undergo ambulation. Patients who were unconscious, had a duration of serebrovascular event (CVE) of more than 6 months, had severe neglect, additional medical problems that may constitute to receive the exercise program, muscle diseases or other neurological pathologies were excluded from the study.

The study was conducted in accordance with the Helsinki Declaration principles. Approval was obtained from the local ethics committee (decision dated 11.06.2012 and numbered 03/24) the patients were informed on the objective and contents of the study and written consent was obtained from them.

Patients admitted within 6 months after the onset of stroke were evaluated as those admitted at $10^{\text {th }}-45^{\text {th }}$ day, $45^{\text {th }}-90^{\text {th }}$ day and $90^{\text {th }}-180^{\text {th }}$ day. Information about age,gender, occupation, duration of disease, location of lesion and affected side of the body, CVE etiology, previous CVE or transient ischemic attack history, comorbid diseases, drugs used and smoking, alcohol use was recorded.

The Beck Depression Inventory(BDI) was used for post-CVE depression screening. BDI a self-report inventory, was used to examine the emotional stability of patients. It consists of 21 items. Each item is a list of 4 statement arranged in increasing severity about a particular symptom of depression. The BDI grades depression as minimal (0-13), mild (14-19), moderate (20-28) and severe (29-36) (6)

To assess sleep disorders; it was investigated whether insomnia (difficulty falling asleep, difficulty waking up, inability to wake up rested etc.), severe somnolence during daytime, and narcolepsy (uncontrollably and suddenly falling asleep)were present (7).

The near visual acuity chart was used to determine visual acuity. Vision levels of full-0.6 were considered very good, 0.6-0.4 were good, 0.4-0.2 were moderate and $\leq 0.1$ were low visual acuity (8). Visual field assessment was made using the confrontation method. Information about whether the patients had hearing loss was obtained from their medical history. The sensory examination included superficial sense, joint position sense and vibration examinations. Neglect phenomenon was assessed using the star cancellation test. The star cancellation test is a screening tool that was developed to detect the presence of unilateral spatial neglect in patients with stroke. It involves patients searching for stars and marking them with a pen on a sheet of paper (9).

Ambulation level was assessed using the Functional Ambulation Scale (FAS) (10); the patients were classified as dependent on physical aid level 2 (stage 1), dependent on physical aid level 1 (stage 2), dependent on supervision (stage 3), independent only on flat surfaces (stage 4) based on their walking independence and aids they use.

The functional independence measure(FIM) was used for functional assessment. The FIM scale assesses physicaland cognitive disability. This scale focuses on the burden of care. Items are scored on the level of asistancerequired for an individual to perform activities of daily living. The scale includes 18 items. Each item is scored from 1 to 7 based on level of independence: 1 represents total dependenceand 7 indicates complete independence. Possible scores range from 18 to 126 (11).

Upper limb motor functions were assessed using the Fugl Meyer Motor Assessment (FMA) (12) and Frenchay Arm test (FAT) (13). The FMA is used in clinical trials and rehabilitation settings that treat people after stroke and is one of the most widely used quantitative measures of motor impairment. Each item on the FMA is rated on a 3 -point ordinal scale $(0=$ can not perform, 1 =performs partially, 2 =performs fully), and items measure motor performance, sensory function, balance, joint range of motion, and joint pain. The upper extremity motor function portion of the FMA is used in this study (maximum score is 66) (12). The FAT is a simple measurement of arm function and is suitable for use with patients recovering from stroke. It takes less than 3 minutes to complete and consists of 5 tasks. The patient receives a score of 1 for each task completed successfully. The patients its at a table with hands in his or her lap and begins each task from this position (13).

Balance was assessed using the functional stretch test and the timed up and go test. Functional Reach test subjects stand comfortably parallel to a wall, make a fist, and raise their arms to 90 degrees of flexion. A yardstick is place parallel to the subject's raised arms. The examiner measures and records the placement of the end of the subject's third metacarpal along the yardstick, this being termed Position I. In Position 2, the subject reaches as far forward as possible without losing his/her balance and the examiner measures and records the placement of the same landmark along the yardstick. Functional reach is defined as the mean difference between Position I and Position 2 over three trials in which each subject participates. If the subject touches the wall or requires any assistance from the examiner, it invalidates the trial. The examiner guards all subjects at a supervision level of assistance during the maneuver (14). In the Timed "Up and Go" test, timed subjects rise from a chair, walk three meters, turn, walk back, and sit down. During this test, subjects wear their routine foot wear. All chairs used have an approximate seat height of $45 \mathrm{~cm}$ and arm rest height of $65 \mathrm{~cm}$. The subjects received no score if they were unable to complete the test or required assistance to refrain from falling during the test (15).

For all patients presence of osteoporosis in the previous history, previous history of fractures, and familial history of fractures with respect to osteoporosis were queried. Complete blood count, total protein, serum calcium, inorganic phosphorus, alkaline phosphatase, $25(\mathrm{OH})$ vitamin $\mathrm{D}$ (the reference range: 
sufficient level $>30 \mathrm{ng} / \mathrm{ml}$, lack of $20-30 \mathrm{ng} / \mathrm{ml}$, failure $<20 \mathrm{ng} / \mathrm{ml}$ ), parathyroid hormone (PTH) levels were measured. The patients' bone mineral density (BMD) values were measured using the Dual Energy X-Ray Absorptiometry (DXA) method at the lumbar spine and femoral neck; and the young adult values (T score) were included in the study. Laboratory analyses, vertebral graphies and BMD measurements of the patients were performed before discharge and repeated during the examination at the $12^{\text {th }}$ month.

Conventional and neurophysiological therapy were applied 2 hours daily, 5 days a week for 1 month on average to all patients included in the study. Training for bedside sitting and for tilt table and/or parallel bar standing and weight-bearing exercises was initiated. Walking and stairs exercises and balance exercises were given to patients who managed to ambulate. The patients' relatives or nursing staff were trained for protection and positioning of the shoulders and taping and shoulder strap were used in patients with flask shoulder. Constraint-induced movement therapy was recommended to patients who had good cognitive functions, are motivated and did not have risk of fall. Mirror treatment was given to patients who could not start active motion.

At the end of the rehabilitation program appropriate ortheses and aids were given to the patients.

\section{Statistical Analysis}

The data were analyzed using SPSS for Windows 11.5 software package. The Shapiro-Wilk test was used to investigate whether the continuous and discrete numeric variables are distributed close to the normal distribution. The descriptive statistics were shown as mean \pm standard deviation or median for the continuous and discrete numeric variables. The categorical variables were expressed as case number and (\%). The significance of the difference in terms of mean values between the groups was examined using the Student's t test and the significance of the difference in terms of median values was examined using the Mann-Whitney $U$ test. Investigations about whether there were any statistically significant differences between the means clinical measurements within the follow-up times was performed using the Dependent t-test, and the significance of the difference in terms of median values was investigated using the Wilcoxon Sign test. All variables found to be $p<0.10$ as a result of univariate statistical analyses were included in the model as candidate factors. The odds ratio for each variable, 95\% confidence interval and wald statistics were calculated. Unless otherwise specified, $\mathrm{p}<0.05$ was considered statistically significant. The minimum required sample size for this study did not calculate.

\section{RESULTS}

In our study $76 \%(n=38)$ of the 50 patients who were included returned for the follow-up examination at the sixth month; 10 patients could not be reached. 2 patients were excluded from the study due to exitus, it was learned that the causes were not fall or fracture. $70 \%(n=35)$ of the 38 patients returned for the follow-up examination at the twelfth month, 3 patients could not be reached.
Fall rates were $2 \%$ (person/month) during the clinical follow-up; $26.3 \%$ during the first sixth months; and $25.7 \%$ between the $6^{\text {th }}$ and $12^{\text {th }}$ months 1 of 35 patients(2.85\%) had wrist fracture on the hemiplegic side during the first six months (Table 1).

\begin{tabular}{lccc}
\hline \multicolumn{4}{l}{ Table 1. Frequency of falls according to follow-up times of patients } \\
\hline Time & n & Fallen & $\%$ \\
\hline First Control & 50 & 1 & 2.0 \\
Second Control & 38 & 10 & 26.3 \\
Third Control & 35 & 9 & 25.7 \\
\hline
\end{tabular}

The patients' sociodemographic and clinical characteristics are shown in Table 2 and Table 3.

Table 2. The patients'sociodemographic and clinical characteristics

\begin{tabular}{|c|c|}
\hline Variables & $n=50$ \\
\hline Age (year) & $60 \pm 13$ \\
\hline Age range (year) & $29-86$ \\
\hline \multicolumn{2}{|l|}{ Genger } \\
\hline Female & 27 (54\%) \\
\hline Male & $23(46 \%)$ \\
\hline \multicolumn{2}{|l|}{ Occupation } \\
\hline Housewife & 27 (54\%) \\
\hline Worker & $6(12 \%)$ \\
\hline Retiree & $10(20 \%)$ \\
\hline Security staff & $3(6 \%)$ \\
\hline Sect leader & $1(2 \%)$ \\
\hline Driver & $2(4 \%)$ \\
\hline Waiter & $1(2 \%)$ \\
\hline \multicolumn{2}{|l|}{ Companion } \\
\hline Family member & 47 (94\%) \\
\hline Care giver & $3(6 \%)$ \\
\hline Date of Stroke & $42(16-180)$ \\
\hline $10-45$ day & 27 (54\%) \\
\hline 45-90 day & $18(36 \%)$ \\
\hline 90-180 day & $5(10 \%)$ \\
\hline \multicolumn{2}{|l|}{ Hemiplegic Side } \\
\hline Right & 22 (44\%) \\
\hline Left & $28(56 \%)$ \\
\hline \multicolumn{2}{|l|}{ Etiology } \\
\hline Thromboemboli & $38(76 \%)$ \\
\hline Haemorrhage & $11(22 \%)$ \\
\hline Subaraknoid haemorrhagia & $1(2 \%)$ \\
\hline Trans Ischemic Attack & $3(6 \%)$ \\
\hline Previous CVE & $14(28 \%)$ \\
\hline Smoking & $19(38 \%)$ \\
\hline Drink alcohol & $5(10 \%)$ \\
\hline Previous history of fractures & $10(20 \%)$ \\
\hline Poststroke depression & $30(60 \%)$ \\
\hline Antidepressant Medications & $26(52 \%)$ \\
\hline Psychotropic Medications & $2(4 \%)$ \\
\hline Sleep disorders & $16(32 \%)$ \\
\hline
\end{tabular}

CVE: cerebrovascular event 


\begin{tabular}{lcc}
\hline \multicolumn{2}{l}{ Table 3. The patients' clinical characteristics } & \\
Variables & N & $\%$ \\
\hline Visual acuity & 5 & 10 \\
$1,0-0,6$ & 16 & 32 \\
$0,6-0,4$ & 21 & 42 \\
$0,4-0,2$ & 8 & 16 \\
$0,1-<0,1$ & & \\
Vision levels & 8 & 16 \\
Low & 21 & 42 \\
Moderate & 16 & 32 \\
Good & 5 & 10 \\
Very good & & \\
Visual field & 40 & 80 \\
Normal & 10 & 20 \\
Disorder & 3 & 6 \\
Neglect phenomenon & 2 & 4 \\
Hearing loss & 21 & 42 \\
Sensory impairment & & \\
FAS & 14 & 28 \\
dependent on physical aid level 2 (stage 1) & 10 & 20 \\
dependent on physical aid level 1 (stage 2) & 19 & 38 \\
dependent on supervision (stage 3) & 7 & 14 \\
independent only on flat surfaces (evre 4) & 28 & 56 \\
Ortheses and aids & 50 & 100 \\
Total & & \\
\hline FAS: Functional Ambulation Scale & & \\
\hline
\end{tabular}

The patients who were included in the study and completed the one-year follow-up period were divided into two groups as fallen and not fallen. The effects of the patients' demographic and clinical characteristics and the changes in the assessment scale scores on falling were examined by comparing the groups. No statistically significant differences were found between the groups in terms of the gender distribution, age, attendants, hemiplegic side, previous CVE history, rates of comorbid diseases, distribution of regularly used drugs, vision level, visual field, neglect phenomenon, hearing loss and deep sensory impairment, sleep disorder, distribution of FAS stage, use of orthoses/ aid,timed up\&go test,FIM, FAT and FM upper limb assessment scale. Statistically significant differences were found between the groups in terms of the Functional Reach Test $(p=0,013)$ (Table 4).

The laboratory measurements of the patients who completed the one-year follow-up period are shown in Table 3. The changes in the laboratory analyses performed before discharge and at the end of the first year in the fallen and not fallen groups are shown in Table 3. Hemoglobin levels of fallen group was statistically lower than the not fallen group $(p=0.020)$ (Table 5).

\section{DISCUSSION}

Falls and fractures are among the most common complications seen after stroke; they significantly increase morbidity and mortality rates; and cause increases in hospital admissions and healthcare expenses. Patients develop fear of falling again, leading to limited activities. This may constitute a significant impediment to the patients' attendance to rehabilitation, and cause social isolation for them (16). We aimed to examine the factors that may affect the falls and fractures which was in stroke patients during the rehabilitation phase and follow-up phase in the first year after discharge. It was aimed to assess the frequency of falls and fractures in early period after stroke.

The fall rates found in our study were $2 \%$ during the clinical followup; and $26.3 \%$ during the first sixth months; and $25.7 \%$ between the $6^{\text {th }}$ and $12^{\text {th }}$ months after discharge. The fall rates in our study were lower than those reported in the literature. The patients and

\begin{tabular}{|c|c|c|c|c|c|}
\hline Variables & Mean ( \pm SD) & Median & Minimum & Maximum & p-value \\
\hline Functional Reach Test & & & & & $0.013^{*}$ \\
\hline Fallen & $10( \pm 5.6)$ & 11 & 1 & 18 & \\
\hline Not fallen & $3.3( \pm 7.4)$ & 3 & -20 & 18 & \\
\hline Timed up\&go test & & & & & 0.160 \\
\hline Fallen & $-52.7( \pm 48.9)$ & -30 & -130 & -2 & \\
\hline Not fallen & $-24.1( \pm 29.1)$ & -18 & -80 & 60 & \\
\hline FIM & & & & & 0.362 \\
\hline Fallen & $23.3( \pm 11.4)$ & 23 & 3 & 41 & \\
\hline Not fallen & $19.6( \pm 14.5)$ & 15 & -14 & 43 & \\
\hline FAS & & & & & 0.224 \\
\hline Fallen & $1.7( \pm 1)$ & 2 & 0 & 3 & \\
\hline Not fallen & $1.1( \pm 1.2)$ & 1 & -2 & 3 & \\
\hline Frenchay Arm Testi & & & & & 0.616 \\
\hline Fallen & $1.1( \pm 0.9)$ & 1 & 0 & 3 & \\
\hline Not fallen & $1.0( \pm 1.3)$ & 1 & 0 & 5 & \\
\hline FM upper limb assessment & & & & & 0.128 \\
\hline Fallen & $16.7( \pm 7.8)$ & 19 & 7 & 29 & \\
\hline Not fallen & $11.5( \pm 11.2)$ & 10.5 & -16 & 44 & \\
\hline
\end{tabular}




\begin{tabular}{|c|c|c|c|c|c|}
\hline Variables & Mean $( \pm)$ & Median & Minimum & Maximum & p-value \\
\hline BMD (femoral neck) & & & & & 0.711 \\
\hline Not fallen & $-1.9( \pm 1.59)$ & -2.3 & -3.7 & 2.0 & \\
\hline Fallen & $-2.1( \pm 1.46)$ & -1.9 & -4.5 & -0.4 & \\
\hline BMD (lumbar spine) & & & & & 0.923 \\
\hline Not fallen & $-1.5( \pm 1.44)$ & -1.9 & -3.9 & 1.7 & \\
\hline Fallen & $-1.5( \pm 1.75)$ & -1.4 & -4.3 & 0.6 & \\
\hline Haemoglobin & & & & & $0.020^{*}$ \\
\hline Not fallen & $13.7( \pm 1.31)$ & 14.0 & 10.3 & 15.3 & \\
\hline Fallen & $12.3( \pm 1.90)$ & 12.9 & 7.4 & 13.6 & \\
\hline Calcium & & & & & 0.693 \\
\hline Not fallen & $9.3( \pm 0.60)$ & 9.5 & 8.3 & 10.5 & \\
\hline Fallen & $9.3( \pm 0.32)$ & 9.3 & 8.8 & 9.9 & \\
\hline Inorganic phosphorus & & & & & 0.868 \\
\hline Not fallen & $4.0( \pm 0.56)$ & 4.1 & 2.8 & 5.0 & \\
\hline Fallen & $4.1( \pm 1.22)$ & 4.1 & 2.8 & 6.9 & \\
\hline Alkaline phosphatase & & & & & 0.562 \\
\hline Not fallen & $79.4( \pm 19.23)$ & 78.0 & 25.0 & 117.0 & \\
\hline Fallen & $75.1( \pm 18.44)$ & 71.0 & 50.0 & 102.0 & \\
\hline Total protein & & & & & 0.971 \\
\hline Not fallen & $6.9( \pm 0.54)$ & 6.9 & 5.7 & 8.1 & \\
\hline Fallen & $6.9( \pm 0.54)$ & 6.8 & 6.3 & 7.5 & \\
\hline Parathyroid hormone & & & & & 0.810 \\
\hline Not fallen & $35.4( \pm 15.04)$ & 37.6 & 10.3 & 70.0 & \\
\hline Fallen & $32.4( \pm 14.89)$ & 40.0 & 10.5 & 49.4 & \\
\hline $25(\mathrm{OH})$ vitamin D & & & & & 0.160 \\
\hline Not fallen & $13.1( \pm 8.48)$ & 11.4 & 4.5 & 47.3 & \\
\hline Fallen & $9.3( \pm 4.10)$ & 9.1 & 2.9 & 17.2 & \\
\hline
\end{tabular}

BMD: Bone Mineral Density, ${ }^{*} \mathrm{p}<0.05$ by the Mann-Whitney $U$ test

their caregivers were recommended to keep a fall diary and asked whether falls occurred after discharge. The low fall rates found suggested that not all falls may have been recorded.

Studies have reported fall-associated fracture rates after stroke as about $1-15 \%$. The study conducted by Forster and Young found that $35 \%$ of falls result in soft tissue injury and $1 \%$ in fractures. In our study, one patient had right wrist fracture on the hemiplegic side during the first six months after stroke and the percentages of fractures occurred during the follow-up period were consistent with the literature. In fallen and not fallen patients no significant differences were found in terms of the affected hemiplegic side, previous CVE history, gender and age, which was consistent with the literature (5).

Post stroke depression is a common complication which was reported in the literature to cause increased morbidity and mortality, restrict rehabilitation and lead to prolonged hospitalization (17). In our study, post stroke depression was found in $60 \%$ of the patients which was consistent with the literature; and no significant relationship was found between fallen and not fallen patients. The rate for post stroke sleep problems was $33 \%$ (18) in other studies, and $32 \%$ in our patients, showing no difference between the groups in terms of sleep disorder. In our study that examined the effects of comorbid diseases and regularly used drugs on falls, no statistically significant difference was found. There are various results in the literature $(18,19,20)$.

Stroke causes balance disorders because of inability to produce fast, accurate, and coordinated muscular patterns. In the literature, it was reported that patients adapt to balance impairments in the long term after stroke, playing a protective role against falls (21). In our study, the effect of the balance improvement on the fallen and not fallen patients were found to be statistically similar. During the 
study period, our patients could learn how to adjust to diseaserelated functional impairment, which may have resulted in a lower risk of falls. In our study, increases in the functional reach test levels were observed in both patient groups, being statistically more significant in fallen patients.

In our study, significantly increased FIM motor scores were found in the tests to assess activity limitations, and the effects of these on falls were not significant. Similarly, Robert et al. found that fallen and not fallen patients were significantly different in terms of FIM scores, and not fallen group had higher FIM scores (22).

After stroke rehabilitation, patients may become more vulnerable to falls as their mobility and independence increase $(23,24)$. We found that our patients'ambulation levels increased, FAS stages improved during the follow-up period and no effect on falls was observed.

Poor upper limb motor function may be expected to lead to falls. It has been reported that upper limb function is a determinative factor for falls (23). In our study, while significant increases were observed in the FM upper limb scale and FAT that were applied to assess upper limb motor functions, no significant differences were found between the groups.

In stroke, impairments in mental functions associated with focal brain lesions occur; and impairments in cognitive functions are common. While there are inadequate studies in the literature to explain the relationship between reduction in cognitive functions and falls, poor cognitive functions of stroke patients prevent them from understanding their existing inabilities; so they try to move more than they are able to do and ignore warnings and these may result in falls $(3,25,26)$. In our study, FIM cognitive scores significantly increased during the first six months after stroke; no significant difference was found between the groups.

Stroke patients have bone mineral loss especially at the paretic side. Age and smoking, that are risk factors for stroke; and weakness and immobility occurring after stroke are risk factors for osteoporosis. Bone resorption develops rapidly after stroke, and later and slower bone loss occurs during the subsequent years. Osteoporosis that begins during the early period after stroke and continues to increase during the first year have influence on post-stroke fractures (27). In our study no significant changes neither at the femoral neck nor the total vertebra levels. No statistically significant differences were found between the fallen and not fallen patients in terms of the changes in the BMD and laboratory analysis values. The hemoglobin levels measured during hospitalization of the fallen patients who completed the 1-year follow-up period were lower and considered statistically significant; however no significant difference was found between the fallen and not fallen patients in terms of the hemoglobin levels measured at the $12^{\text {th }}$ month.

The effects of balance disorder and poor upper limb motor functions that may be risk factors for falls and fractures were not significant in the fallen patient group because of the small number of the patients who were included in the study and fall.
No significant changes were found in BMD values during the one-year follow-up period, and it was concluded that progressed osteoporosis and weakened bones leading to increased risk of fractures may be observed with longer follow-up periods.

The most important limitation of our study is the low number of patients and the fact that our follow-up period is limited to one year. The reason of the short follow-up period was that our patients did not return for follow-up during long periods and therefore excluded from the study. However, some of the patients who left the study before the completion of the follow-up period.

\section{CONCLUSION}

Fall after stroke is common during acute period, rehabilitation phase and chronic period. Early rehabilitation after stroke may increase balance and upper limb motor functions leading to lower rates of falls and fractures. Progressed osteoporosis and weakened bones leading to increased risk of fractures may be observed with longer follow-up periods.

Informed Consent: Patients were informed on the objective and contents of the study and written consent was obtained from them.

Compliance with Ethical Standards: The study was conducted in accordance with the Helsinki Declaration principles. Approval was obtained from the local ethics committee (decision dated 11.06.2012 and numbered 03/24)

Peer-review: Externally peer-reviewed.

Author Contributions: Concept - TES; Design - TES; Supervision - AÇ; Fundings - TES, HS; Materials - TES, AÇ; Data Collection and/or Processing - TES, FAÇ; Analysis and/ or Interpretation - AÇ, HS; Literature Search - TES; Writing Manuscript - TES, HS; Critical Review - FAÇ

Conflict of Interest: No conflict of interest was declared by the authors.

Financial Disclosure: The authors declared that this study has received no financial support.

\section{REFERENCES}

1. Dalyan Aras $M$, Çakçı A. İnme rehabilitasyonu. İçinde: Oğuz $H$, Dursun E, Dursun N, editörler. Tıbbi Rehabilitasyon. İstanbul: Nobel Tıp Kitabevi; 2004. ss.589-617.

2. Batchelor FA, Mackintosh SF, Said CM, Hill KD. Falls after stroke. Int J Stroke 2012;7:482-490. [CrossRef]

3. Simpson LA, Miller WC, Eng JJ. Effect of stroke on fall rate, location and predictors: a prospective comparison of older adults with and without stroke. PLoS One 2011;6:e19431. [CrossRef]

4. Langhorne P, Stott DJ, Robertson L, et al. Medical complications after stroke: a multicenter study. Stroke 2000;31:1223-1229. [CrossRef]

5. Mackintosh SFH, Hill K, Dodd KJ, Goldie P, Culham E. Falls and injury prevention should be part of every stroke rehabilitation plan. Clin Rehabil 2005;19:441-451. [CrossRef]

6. Beck AT, Ward CH, Mendelson M, Mock J, Erbaugh J. An inventory for measuring depression. Arch Gen Psychiatry 1961;4:561-571. [CrossRef]

7. Thaxton LL, Patel AR. Sleep Disturbances: epidemiology, assesment and treatment. In: Zasler ND, Katz DL, Zafonte RD. editors. Brain Injury Medicine. New York: Demos Medical Publishing; 2007. pp.557-575. 
8. Ganesan K, Shalini D. Design of Customizable Automated Low Cost Eye Testing System. J Clin Diagn Res 2014;8:85-87. [CrossRef]

9. Wilson B, Cockburn J, Halligan P. Development of a behavioural test of visuo-spatial neglect. Arch Phys Med Rehabil 1987;68:98-102.

10. Holden MK, Gill KM, Magliozzi MR. Gait assessment for neurologically impaired patients, standards for outcome assessement. Phys Ther 1986;66:1530-1539. [CrossRef]

11. Kidd D, Stewart G, Baldry J, et al. The Functional Independence Measure: A comparative validity and reliability study. Disabil Rehabil 1995;17:10-14. [CrossRef]

12. Fugl-Meyer AR, Jaaskö L, Olsson S, Steglind S. The post stroke hemiplejik patient: A method for evaluation of physical performance. Scand J Rehab Med 1975;7:13-31.

13. Wade DT. Measurement in Neurological Rehabilitation. Oxford University Press; 1992.

14. Hill KD, Bernhardt J, MC Gann AM, Maltese D. A new test of dynamic standing balance for stroke patients: reliability, validity and comparison with healthy elderly. Physiother Can 1996;(fall):257-262. [CrossRef]

15. Siggeirsdottir $\mathrm{K}$, Jonsson BY, Jonsson $\mathrm{H}$, Iwarsson $\mathrm{S}$. The Timed 'Up\&Go' is dependent on Chair Type. Clin Rehabil 2002;16:609-616. [CrossRef]

16. Langhorne P, Stott DJ, Robertson L, et al. Medical complications after stroke: A multicenter study. Stroke 2000;31:1223-1229. [CrossRef]

17. Hyndman D, Asburn A, Stack E. Fall event among people with stroke living in the community: Circumstances of falls and Characteristics of fallers. Arch Phys Med Rehabil 2002;83:165-170. [CrossRef]

18. Leipzing RM, Cumming RG, Tinetti ME. Drugs and falls in older people: a systematic review and meta-analysis: I. Psychotropic drugs. J Am Geriatr Soc 1999;47:30-39. [CrossRef]
19. Machintosh SF, Hill KD, Dodd KJ, Goldie PA, Culham EG. Balance skore and history of falls in hospital predict recurrent falls in the 6 months following stroke rehabilitation. Arch Phys Med Rehabil 2006;87:1583-1589. [CrossRef]

20. Kerse N, Parag V, Feigin VL, et al. Falls after stroke: results from the Auckland Regional Community Stroke (ARCOS) study 2002-2003. Stroke 2008;39:1890-1893. [CrossRef]

21. Harris JE, Eng J, Marigold DS, Tokuno CD, Louis CL. Relationship of balance and mobility to fall incidence in people with chronic stroke. Phys Ther 2005;85:150-158. [CrossRef]

22. Teasell R, McRae M, Foley N, Bhardwaj A. The Incidence and Consequences of Falls in Stroke Patients During Inpatient Rehabilitation: Factors Associated With High Risk. Arch Phys Med Rehabil 2002;83:329-333. [CrossRef]

23. Asburn A, Hyndman D, Pickering R, Yardley L, Harris S. Predicting people with stroke at risk of falls. Age Ageing 2008;37:270-276. [CrossRef

24. Baetens $T$, de Kegel A, Calders P, Vanderstraeten G, Cambier D. Prediction of Falling Among Stroke Patients in Rehabilitation. J Rehabil Med 2011;43:876-883. [CrossRef]

25. Campbell GB, Matthews JT. An integrative review of factors associated with falls during post-stroke rehabilitation. J Nurs Scholarsh 2010;42:395-404. [CrossRef]

26. Liu-Ambrose T, Pang MYC, Eng J. Executive functioning is independently associated with performances of balance and mobility in community dwelling older adults after mild stroke: implications for falls prevention. Cerebrovasc Dis 2007;23:203-210. [CrossRef]

27. Jorgensen $L$, Jacobsen BK. Functional status of the paretic arm affects the loss of bone mineral in the proximal humerus after stroke: a oneyear prospective study. Calcif Tissue Int 2001;68:11-15. [CrossRef] 